\title{
AVALIAÇÃO DO BACKGROUND DA MINA DE ITATAIA-CEARÁ EM PROCESSO PRÉ- EXPLORATÓRIO
}

\author{
D. N. LOPES ${ }^{1}$, R. N. S. LOPES ${ }^{2}$ \\ ${ }^{1}$ Universidade Estadual do Rio Grande do Norte, ${ }^{2}$ Instituto Potiguar de Desenvolvimento de Comunidades \\ deboranogueira@hotmail.com.br ${ }^{1}$
}

Submetido 20/03/2017 - Aceito 20/02/2018

DOI: $10.15628 /$ holos. 2018.5808

\begin{abstract}
RESUMO
O local da pesquisa situa-se na Fazenda Itataia, em Santa Quitéria no Estado do Ceará. Enquadrando-se na Província Borborema, no Domínio Ceará Central, com um pacote de rochas supracrustais de natureza metassedimentar, sendo constituído dominantemente por mármores, xistos e gnaisses a duas micas, com granada e/ou silimanita, rochas calcissilicáticas e quartzitos metamorfizados em fácies anfibolito alto. A jazida de natureza fósforo-uranífera, ocorre sob a forma de colofanito uranífero, e o corpo principal de minério tem comprimento de 800 metros e largura variável de 250 a 400 metros. O minério ocorre desde a superfície até a profundidade de aproximadamente $180 \mathrm{~m}$. Os estudos mineralógicos dos solos dessa região são escassos, entretanto, esse conhecimento é de grande importância, tanto na caracterização e classificação dos solos, como na elucidação de sua gênese, onde assume
\end{abstract}

relevante importância a classificação do resíduo pesado das frações areia. A caracterização desses solos dados se deu com o auxílio do mapa dos solos do Estado do Ceará, da Embrapa, e com a contribuição da técnica de Difração de Raios-X (DRX) que corresponde a uma das principais técnicas de caracterização microestrutural de materiais cristalinos, onde, de todos os métodos da química analítica para a caracterização de matérias, somente a DRX é capaz de fornecer informações qualitativas e quantitativas dos minerais constituintes de uma mistura. Portando, tem-se que a área estudada está inserida em uma região com Argissolos vermelho/amarelo eutróficos, com inclusões de luvissolos e neossolos litólicos eutróficos, com uma predominância de três minerais: quartzo, fluoropatita, carbonato de cálcio e óxido de urânio, além da presença das principais classes de argilosminerias.

PALAVRAS-CHAVE: Fazenda Itataia, Solos, Difração de Raio-X.

\section{EVALUATION OF THE BACKGROUND OF THE ITATAIA-CEARÁ MINE IN A PRE- EXPLORATORY PROCESS}

\section{ABSTRACT}

The research site is located at Fazenda Itataia, in Santa Quitéria, State of Ceará. It is located in the Borborema Province, in the Central Ceará Domain, with a packet of supracrustal rocks of metassedimentary nature, being dominantly constituted by marble, schist and gneisses to two micas, with grenade and / or sillimanite, calcissilictic rocks and metamorphized quartzites in amphibolite facies high. The phosphorusuraniferous deposit occurs as a uraniferous colophane, and the main ore body is 800 meters in length and variable in width from 250 to 400 meters. The ore occurs from the surface to the depth of approximately $180 \mathrm{~m}$. The mineralogical studies of the soils of this region are scarce, however, this knowledge is of great importance, both in the characterization and classification of the soils, and in the elucidation of its genesis, where the classification of the heavy residue of the sand fractions is of importance. The characterization of these soil data was done with the aid of the Ceará State land map of Embrapa and with the contribution of the X-ray Diffraction (XRD) technique that corresponds to one of the main techniques of microstructural characterization of crystalline materials, where, of all methods of analytical chemistry for the characterization of materials, only the XRD is able to provide qualitative and quantitative information of the constituent minerals of a mixture. The study area is located in a region with eutrophic red / yellow Argisols, with inclusions of luvisols and eutrophic lithole neosols, with a predominance of three minerals: quartz, fluoropatite, calcium carbonate and uranium oxide. of the presence of the main classes of clay minerals.

KEYWORDS: Itataia farm, Soils, x-ray Diffraction. 


\section{INTRODUÇÃO}

Na década de 70, a Nuclebrás, atual INB iniciara os estudos na Jazida de Itataia, através de um programa de prospecção radiométrica, descobrindo as rochas fosfóro-uraníferas, o que desde então acarretou inúmeros estudos em escala regional e de detalhes nessa área. A jazida localiza-se no centro-norte do Estado do Ceará, no município de Santa Quitéria, distando 211 km da capital, e é a maior mina de urânio físsil do Brasil, além de conter fosfato e mármore, sendo responsável por $46 \%$ do urânio prospectado no país. A jazida é de natureza fósforo-uranífera, ocorrendo sob a forma de colofanito uranífero, e o corpo principal de minério ocorre numa elevação, tendo comprimento de 800 metros e largura variável de 250 a 400 metros.

Os Estudos mineralógicos dos solos dessa região são escassos, entretanto, esse conhecimento é de grande importância, tanto para a caracterização e classificação dos solos, como para a elucidação de sua gênese, onde assume relevante importância o estudo do resíduo pesado das frações areia.

A mineralogia das frações areia e silte são constituídas, em geral, por minerais resistentes ao intemperismo, como quartzo, além de outros minerais primários em quantidades variáveis, como olivinas, anfibólios, piroxênios, feldspatos e micas (Buckman, 1976; Fontes, 2002). A fração argila é constituída, via de regra, por minerais de natureza secundária, resultantes dos processos de alteração física, química e biológica, independentemente de terem sido formados in situ ou transportados (Allen \& Hajek, 1989; Fontes, 2002). Neste contexto, fica clara a importância da caracterização mineralógica do solo para compreender o comportamento físico-químico do mesmo.

A técnica de difração de raios-X (DRX) corresponde a uma das principais técnicas de caracterização microestrutural de materiais cristalinos, onde, de todos os métodos da química analítica para a caracterização de matérias, somente a difração de raios- $X$ é capaz de fornecer informações qualitativas e quantitativas dos minerais constituintes de uma mistura (Brindley \& Brown, 1980). Portanto, dada a dimensão e a importância regional e nacional da jazida, o presente trabalho aprofunda os conhecimentos sobre a composição mineralógicas nos solos da região de Itataia no estado Ceará.

\section{EMBASAMENTO TEÓRICO}

\subsection{GEOLOGIA REGIONAL}

\subsubsection{PROVÍNCIA DA BORBOREMA}

A área estudada está situada na Província Borborema (Almeida et al., 1981), no Domínio Ceará Central na qual se encontra no nordeste do Brasil é constituída por terrenos précambrianos de idade variando entre o Arqueano e o Neoproterozóico, na qual, foram intensamente deformados e metamorfizados ao final do Neoproterozóico durante a orogênese brasiliana (Brito Neves, 1975; Caby et al., 1991, 1995; Jardim de Sá, 1994). 
A Província Borborema propriamente dita estende-se ainda por baixo da bacia sedimentar da Parnaíba e parece incluir também a chamada faixa Araguaia, parte setentrional da Província tectônica Tocantins (Almeida et al., 1977), constituindo uma vasta região com mais de 450.000 $\mathrm{km}^{2}$. A província é formada por um conjunto de grandes segmentos crustais (geralmente limitados por extensas zonas de cisalhamento preferencialmente transcorrentes), os quais comportam proporções variadas de rochas do embasamento Paleoproterozoico (com núcleos arqueanos preservados), rochas supracrustais meso- a Neoproterozoicas e granitoides Neoproterozoicos (Van Schmus et al., 1998). O fato é que, esse arcabouço foi recortado tardiamente por duas megatranscorrências destras (lineamentos Patos e Pernambuco), de direção E-W, que dividem a Província Borborema em três sub - Províncias: Borborema Setentrional, Zona Transversal e Borborema Meridional. De leste para Oeste, por sua vez, a Sub Província Borborema Setentrional pode ser subdividida em quatro domínios separados por megazonas de cisalhamento dúctil de leste para oeste: Domínio Rio Grande do Norte, Domínio Orós - Jaguaribe, Domínio Noroeste Ceará e Domínio Ceará Central (Brito Neves et al., 2000), onde localiza-se a área analisada.

\subsubsection{DOMÍNIO CEARÁ CENTRAL}

O Domínio Tectônico Ceará Central é a mais extensa unidade geotectônica da região noroeste da Província Borborema, e a de maior expressão no território do estado do Ceará.

É produto de uma longa e complexa história geológica, iniciada no Arqueano, refletido por vários episódios de acresção crustal e ciclos orogenéticos com atividades magmáticas, metamórficas e deformacionais. Encontra-se delimitado a oeste pelo lineamento Transbrasiliano e a leste pelo Lineamento Senador Pompeu, que apresenta um significativo núcleo de rochas arqueanas reunidas no Maciço de Tróia (Brito Neves 1975, Pessoa et al., 1986 e 1999 (Fetter, 1999).

Sendo constituído, segundo Fetter (1999), em quatro principais unidades lito-estruturais, de acordo com a concepção mais aceita: 1) Embasamento Arqueano, 2) Terrenos Acrescionários do Paleoproterozóico, 3) Terreno Santa Quitéria e 4) Coberturas Neoproterozoicas.

\subsubsection{EMBASAMENTO AREQUEANO}

Os afloramentos de terrenos arqueanos do Ceará Central estão limitados à sua porção sul/sudeste, na região de Pedra Branca e Mombaça. Constituído por gnaisses cinza (grey gneisses), derivados de protólitos plutônicos de natureza essencialmente tonalítica/ granodiorítica, e rochas supracrustais formando associação do tipo greenstone-gnaisses (Pessoa \& Archanjo, 1984; Caby \& Arthaud, 1986; Caby et al.,1995)

A primeira datação disponível confirmando a idade destas rochas, antigamente inseridas na unidade denominada Complexo Pedra Branca, corresponde a uma isócrona Rb-Sr em rocha total de ortognaisses graníticos com idade de $2540 \pm 60$ Ma (Pessoa et al., 1986).

Com aproximadamente $6.000 \mathrm{~km}^{2}$, recortado pela zona de cisalhamento dúctil de Sabonete-Inharé, o bloco apresenta limites ainda mal definidos, em grande parte por causa das 
grandes semelhanças litológicas que apresenta com os terrenos paleoproterozóicos vizinhos (Fetter, 1999).

\subsubsection{TERRENOS ACRESCIONÁRIOS DO PALEOPROTEROZÓICO}

Constituido por paragnaisses e ortognaisses diversos situados entre o Terreno Santa Quitéria e a zona de cisalhamento Senador Pompeu (ZCSP), e correspondem ao Grupo Itatira e a uma parte do Grupo Ceará, que é constituído por rochas paraderivadas, com quartzitos basais seguidos de xistos, gnaisse e carbonatos, fechando a sequência.

Estes terrenos evoluíram provavelmente a partir de uma série de terrenos do tipo arco de ilhas, em um intervalo de 50 Ma durante a orogênese Transamazônica (2.0 Ga), aparentemente, sem a participação de materiais mais antigos (Fetter, 1999).

\subsubsection{TERRENO SANTA QUITÉRIA}

Está alinhado segundo a direção NE-SW, cobrindo uma área de $40.000 \mathrm{~km}^{2}$ e representa significante parte dos complexos granitóides do DCC. Interpreta-se esse complexo como sendo uma suíte magmática originada em ambiente de arco continental com sucessivos episódios magmáticos. Composto por migmatitos e granitóides que variam em composição de dioritos a granitos, o arco de Santa Quitéria também se encontra flanqueado por sequências de ante- e retro-arco (Fetter et al., 2003). Essas sequências estão representadas respectivamente pelo Grupo Martinólope do Domínio Médio Coreaú e pelo Grupo Independência, no DCC.

Datações U-Pb realizadas (Fetter, 1999) resultaram em idades entre 637 e 623 Ma para granitóides deformados do Batólito Santa Quitéria, e ainda idades modelo (TDM) variando entre 0.86 a $1.92 \mathrm{Ga}$, sugerindo uma fonte mista para a origem dos granitóides. Castro et al. (2005) obteve idades U-Pb similares para as rochas deste batólito, variando entre 620 a $611 \mathrm{Ma}$.

\subsubsection{COBERTURAS NEOPROTEROZOICAS}

Composta por uma série de ocorrências de rochas supracrustais que apresentam metamorfismo em fácies anfibolito alto em pressões moderadas a elevadas e um bandamento tectônico de transposição de baixo ângulo caracterizando um sistema de nappes neoproteozóicas alóctones sobre o embasamento paleoproterozóico subjacente (Caby \& Artahud 1986; Castro, et al. 2005).

As coberturas são formadas por rochas de várias idades, mas, a deposição ocorreu no Neoproterózoico. As idades modelos de $\mathrm{Nd}\left(\mathrm{T}_{\mathrm{DM}}\right.$ ) variam entre 2,28 e 2,47 Ga (Van Schmus et al, 1998). Idade U-Pb em cristais de zircão apontam a deposição destas rochas em um ambiente de rifte e a participação de materiais mais jovens do que as áreas fontes do Paleoproterozóico. Ainda foi sugerido por esses autores a correlação entre as rochas supracrustais da região de Independência (Ceará), Grupo Martinópolis (NW do Ceará) e o Grupo Seridó (Rio Grande do Norte e Paraíba).

$\mathrm{Na}$ região de Independência foi reconhecida uma zonação metamórfica do tipo barroviano invertida em grandes nappes do estilo himalaiano. O sentido de transporte das 
estruturas nessa região relacionadas a tectônica tangencial tem sido descrito para Sul, ou SE-SW (Caby \& Artahud, 1986).

\subsubsection{GEOLOGIA DA REGIÃO DE ITATAIA}

Os estudos geológicos realizados pela Nuclebrás permitiram reconhecer para a região de Itataia um ambiente geotectônico, representado por metassedimentos que compõem o Grupo Itataia, posicionado no Paleoproterozóico, através dos resultados dos estudos geocronológicos extraídos da bibliografia, relacionando-o ao Ciclo Transamazônico e com efeitos posteriores de remobilização nos ciclos tectônicos subsequentes.

A área da jazida de Itataia contém duas dessas unidades do Grupo Ceará. A mais antiga, do paleoproterozóico $(\sim 2,1 \mathrm{Ga})$, compreende terrenos granito-gnáissicos granodioríticos a tonalíticos, em parte migmatizados. Nesta unidade insere-se o Complexo Tamboril Santa Quitéria de Castro et al. (2005), ao qual se associam vários corpos graníticos e pegmatóides brasilianos e rochas máficas e ultramáficas de idade indefinida. A segunda consiste de uma sequência supracrustal meso- a neoproterozóica composta por rochas metassedimentares terrígenas com predominância de xistos e gnaisses a duas micas, granada e sillimanita contendo intercalações lenticulares de gnaisses calcissilicáticos, quartzitos, anfibolitos, leptinitos e camadas de mármores calcítico e dolomítico, referidas na literatura como Grupo Itataia (Mendonça et al., 1982), onde, nela hospeda-se o depósito fósforo-uranífero que em termos litoestratigráficos, são identificadas duas unidades litoestratigráficas: o Grupo Itataia e o Complexo Tamboril Santa Quitéria.

O Grupo Itataia agrupa um pacote de rochas supracrustais de natureza metassedimentar, sendo constituído dominantemente por mármores, xistos e gnaisses a duas micas, com granada e/ou silimanita, rochas calcissilicáticas e quartzitos metamorfizados em fácies anfibolito alto. Entretanto, verifica-se, localmente, ao seio das rochas metassedimentares terrígenas, níveis delgados de anfibolitos e horizontes mais espessos de leptinitos, com algumas dezenas de metros. Estas rochas supracrustais têm sido agrupadas, normalmente, em 04 formações: I) Formação Serra do Céu, unidade mais inferior, com migmatítos, leptinitos e gnaisses; II) Formação Laranjeira com quartzitos puros e micáceos; III) Formação Barrigas, com gnaisses migmatítos ou não e, no topo; IV) Formação Alcantil, com mármores cristalinos e calcissilicática onde se concentram o minério fósforo-uranífero (Mendonça et al., 1985).

O Complexo Tamboril/Santa Quitéria é representado por rochas gnáissicas e migmatíticas de composição granodiorítica a tonalítica atribuídas ao Arco Magmático de Santa Quitéria (Fetter, 1999).

A Jazida de Itataia, segundo Mendonça et al. (1980 e 1985) são encontrados três os principais tipos litofógicos mineralizados em fosfato e urânio: o colofanito, minério principal, a brecha carbonosa e epissienito. Mas, a mineralização ainda ocorre de modo disseminado nos mármores, cálcio-silicáticas e gnaisses, preenchendo fraturas e planos de foliação. $O$ fato é que, a cronologia da origem do colofanito é ainda duvidosa. O posicionamento desse evento no Cambro-Ordoviciano é correlacionado à ocorrência de fragmentos rolados do colofanito nos 
conglomerados basais da Formação Serra Grande, de idade siluro-devoniana, ou preenchendo os interstícios de rochas pegmatóides e pissienitizadas no final do ciclo Brasiliano, de idade eocambriana (Nuclebrás, 1984).

\subsubsection{GEOLOGIA ECONÔMICA}

A jazida é de natureza fósforo-uranífera, ocorrendo sob a forma de colofanito uranífero, e o corpo principal de minério ocorre numa elevação, tendo comprimento de 800 metros e largura variável de 250 a 400 metros. O minério ocorre desde a superfície até a profundidade de 180 metros. As reservas lavráveis do corpo principal são da ordem de 8.882 .000 t de $\mathrm{P}_{2} \mathrm{O}_{\mathrm{s}}$ e $79.319 \mathrm{t}$ de $\mathrm{U}_{3} \mathrm{O}_{8}$, sendo $79.500 .000 \mathrm{t}$ de minério. Só de colofanito maciço as reservas atingem um total de 19.300.000 t. As reservas de calcário associado ao minério são da ordem de $32.000 .000 \mathrm{t}$.

A origem para a mineralização fósforo-uranífera estaria relacionada a rochas sedimentares depositadas em zonas de plataforma marinha rasa e/ou restrita e que o fosfato seria originalmente oriundo do reservatório oceânico. Neste contexto, a precipitação do fosfato ocorreria devido ao aumento da concentração de $\mathrm{HPO}_{4}{ }^{-2}$ como consequência da movimentação de águas frias do fundo oceânico em correntes ascendentes que se misturariam as águas superficiais mais quentes das bordas de bacias. Já a fonte do urânio, seria dominantemente terrígena, relacionada à lixiviação do embasamento continental preexistente e se depositaria em ambiente marinho confinado com fortes influências continentais. Analisando a composição isotópica e química do minério e mármores e rochas cálcissilicáticas associados à mineralização, tais autores sugeriram que a interação entre esses fluidos parece ter ocorrido durante um estágio pós-deformacional. Logo, segundo o modelo proposto, a mineralização seria de origem predominantemente sedimentar, com reconcentração por processos tectono-metamórficos e posterior enriquecimento por processos supergênicos (Castro et al., 2005).

A Jazida de Itataia além de ser a de maior teor de fosfato do país ( $11 \%$ de $\mathrm{P}_{2} \mathrm{O}_{5}$ ), é a maior jazida de urânio brasileira (79.319 t de $\mathrm{U}_{3} \mathrm{O}_{8}$, medidas). Além do mármore associado ao fosfato e urânio, ainda possui reservas de $300.000 .000 \mathrm{~m}^{3}$ de mármores que podem ser lavrados para rochas ornamentais, cimento, cal, tintas e corretivo de solo (INB, 2014).

\section{3 ÁREA DE ESTUDO}

O local da pesquisa situa-se na Fazenda Itataia (Figura 01), estando a jazida localizada a $211 \mathrm{~km}$ da capital do Estado, Fortaleza, e a cerca de $45 \mathrm{~km}$ a sudoeste da sede municipal de Santa Quitéria, na Microrregião de Santa Quitéria. 


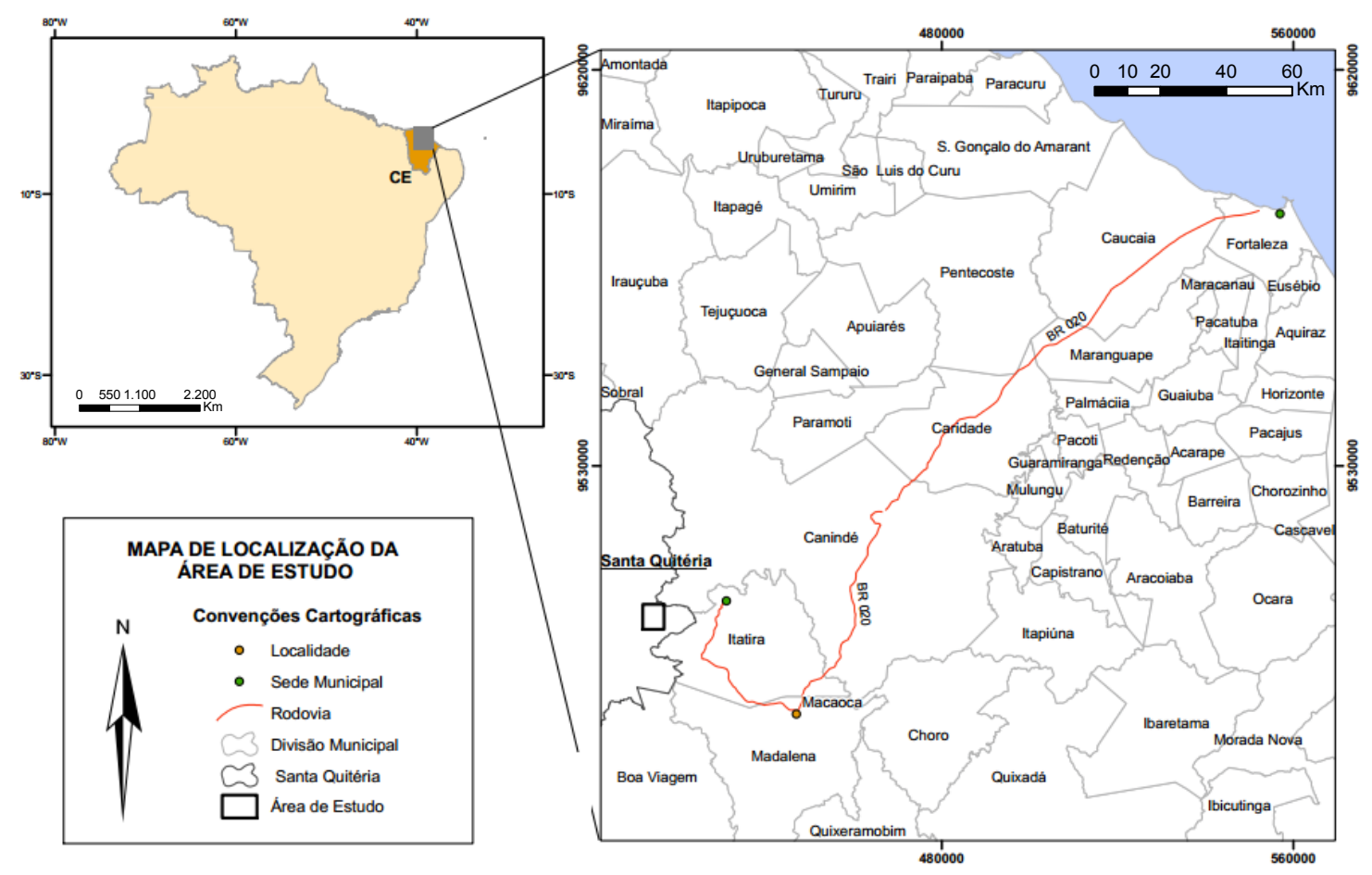

Figura 01: Mapa de Localização

Fonte: Autor

As explorações mineiras futuras de maior interesse na região são concentrações fósforo uraníferas que ocupam parte de uma pequena elevação. Trata-se de um projeto de exploração a céu aberto, inserido na Folha Itatira - SB.24-V-B-V (1:100.000), abrangendo duas unidades tectônicas conhecidas como Cinturão Dobrado de Jaguaribe e o Maciço de Santa Quitéria. O principal corpo mineral tem uma extensão aproximada de $800 \mathrm{~m}$ na direção leste - oeste, por 250 a 400m de largura na direção norte-sul e ocorre desde a superfície até $180 \mathrm{~m}$ de profundidade (INB, 2014). A lavra do Projeto Santa Quitéria será realizada a céu aberto e em cava, sendo a extração feita por meio de bancadas de até $10 \mathrm{~m}$ de altura.

A superfície total da área estudada é de $1,44 \mathrm{Km}^{2}$, delimitada pelas seguintes coordenadas UTM:

Tabela 1: Coordenadas UTM da área estudada

\begin{tabular}{c|c|c}
\hline Vértice & UTM E $(\mathrm{m})$ & UTM N (m) \\
\hline 1 & 9496400 & 413800 \\
2 & 9496400 & 414800 \\
3 & 9495200 & 414800 \\
4 & 9495200 & 413800 \\
\hline
\end{tabular}

Com base em dados referentes ao mapa dos solos do Estado do Ceará da Embrapa, temse que a área estudada está inserida em uma região com prevalência de argissolos Vermelho/Amarelo eutróficos, neossolos litólicos e com inclusões de luvissolos. 
Tem-se que na Jazida de Itataia, segundo Mendonça et al. (1980 e 1985) são encontrados três os principais tipos litofógicos mineralizados em fosfato e urânio: o colofanito, minério principal, a brecha carbonosa e epissienito. Mas, a mineralização ainda ocorre de modo disseminado nos mármores, cálcio-silicáticas e gnaisses, preenchendo fraturas e planos de foliação. $O$ fato é que, a cronologia da origem do colofanito é ainda duvidosa. O posicionamento desse evento no Cambro-Ordoviciano é correlacionado à ocorrência de fragmentos rolados do colofanito nos conglomerados basais da Formação Serra Grande, de idade siluro-devoniana, ou preenchendo os interstícios de rochas pegmatóides e pissienitizadas no final do ciclo Brasiliano, de idade eocambriana (Nuclebrás, 1984).

\section{METODOLOGIA}

Com base nas técnicas de amostragem de solos por distribuição aleatória estratificada dos pontos (ABNT, 2011), em que foi determinada basicamente pelo tamanho e forma do alvo, onde a coleta das amostras se deu em intervalos regulares ao longo de linhas também regularmente espaçadas. Foram coletadas 42 amostras em estações definidas a aproximadamente $200 \mathrm{~m}$ de distância entre elas em uma área de $1,44 \mathrm{~km}^{2}$ (Figura 2), assegurando que todas as subáreas que compõe o local investigado fossem amostradas.

Ao final desse processo, as amostras já estavam devidamente preparadas para a etapa laboratorial seguinte, a difração de raios- $X$ (DRX), que corresponde a uma das principais técnicas de caracterização microestrutural de materiais cristalinos, onde, de todos os métodos da química analítica para a caracterização de matérias, somente a difração de raios- $X$ é capaz de fornecer informações qualitativas e quantitativas dos minerais constituintes de uma mistura (Brindley \& Brown, 1980).

Para análise de solos por DRX, geralmente utiliza-se o método do pó, em que o comprimento de onda é mantido constante e se varia o ângulo de difração. Como resultado se obtém uma representação gráfica do arranjamento atômico no retículo cristalino (Cullity, 1978; Brindley \& Brown, 1980; Schulze, 1989). A intensidade dos picos de difração fornece uma base para a estimativa da concentração dos minerais presentes na amostra, e é afetada pelos seguintes fatores: fator de polarização, fator de estrutura, fator de multiplicidade, fator de Lorentz, fator de absorção e fator de temperatura, os quais devem ser considerados para análise quantitativa (Hill \& Howard, 1987; Cullity, 1978). Há vários fatores em relação à natureza física e química da amostra, como a descontinuidade nos cristais, variação na composição química e presença de substâncias amorfas que podem influenciar muito na intensidade de difração e, portanto, na validade da estimativa quantitativa dos minerais (Whittig, 1965; Hill \& Madsen, 2006). 


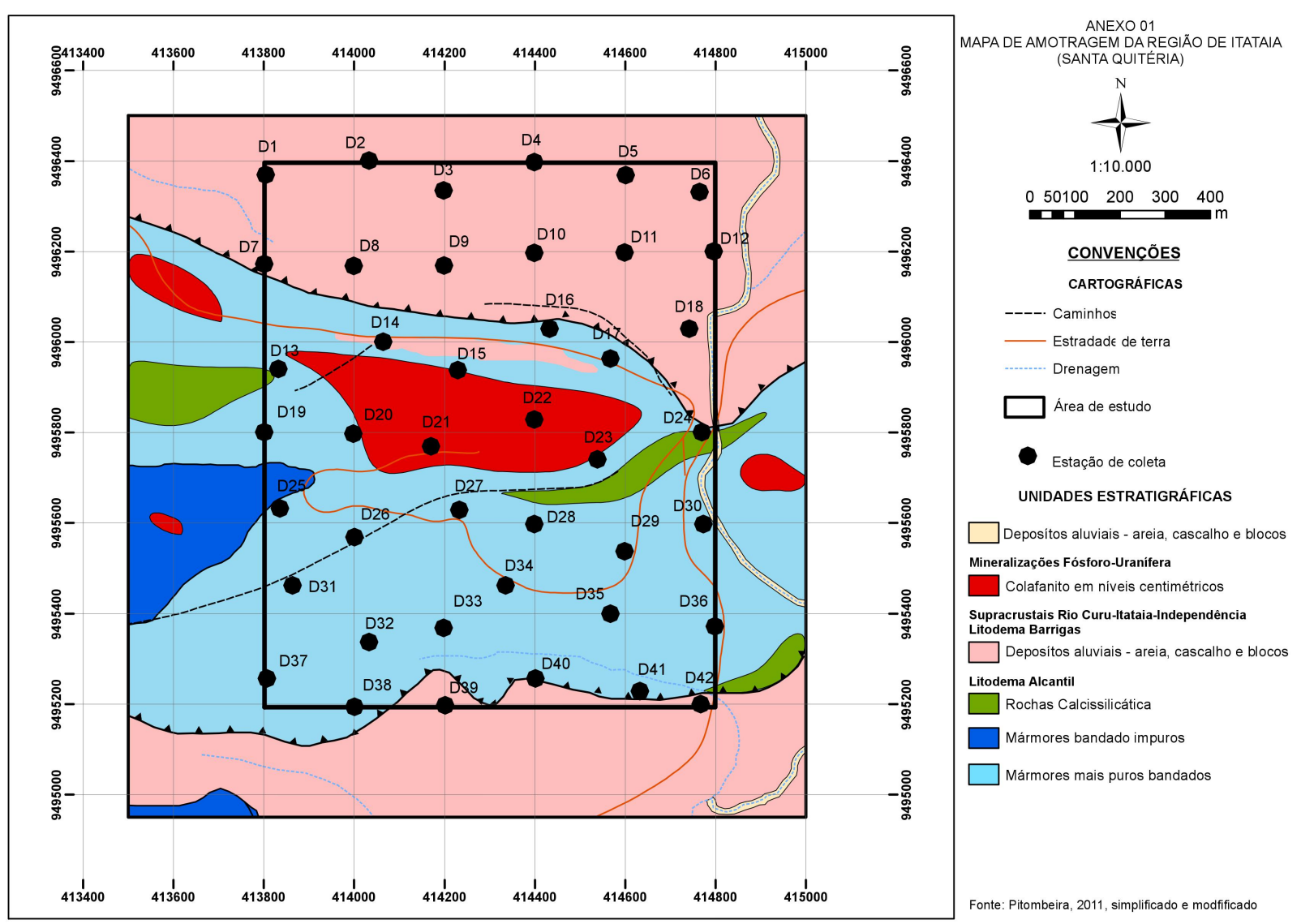

Figura 2: Mapa de amostragem de coleta de amostras

\section{RESULTADOS}

Como resultado da análise tem-se o difratograma de raios- $X$, que consiste em um diagrama no qual se relacionam as posições de picos de difração, assinaladas no eixo das abscissas, com as suas respectivas intensidades, situadas no eixo das ordenadas.

As posições dos picos de difração encontram-se determinadas com a unidade $2 \theta$; isso ocorre porque, na geometria Bragg-Brentano, as medidas de difração são feitas com o tubo de raios- $X$ fixo e com o detector posicionado $2 \theta$ em graus, em relação à direção do feixe incidente. $A$ intensidade dos picos de difração de um mineral depende de fatores relacionados à sua composição química e estrutura cristalina, às características geométricas da medida, ao comprimento de onda da radiação utilizada e a efeitos térmicos. Além dos fatores anteriormente mencionados, outros fatores exercem influência na intensidade de difração, são eles: orientação preferencial, contraste de absorção e extinção.

Com base nos picos de difratogramas de raios-X e nos dados obtidos observou-se que das 42 amostras coletadas, $100 \%$ possui quartzo $\left(\mathrm{SiO}_{2}\right), 26,08 \%$ das amostras contêm fluorapatita $\left(\mathrm{Ca}_{5}\left(\mathrm{PO}_{4}\right)_{3} \mathrm{~F}\right), 13,04 \%$ tem a presença de carbonato de cálcio $\left(\mathrm{CaCO}_{3}\right)$ além de 6,52\% das amostras tem a presença de urânio, referindo-se assim a uma anomalia (Tabela 02). 
Tabela 2: Constituintes mineralógicos predominantes na área estudada, detectado a partir de estudos de DRX.

\begin{tabular}{c|c|c}
\hline Nome do composto & Fórmula Química & Ocorrência \\
\hline Quartzo & $\mathrm{SiO}_{2}$ & $100 \%$ \\
Fluoropatita & $\mathrm{Ca}_{5}\left(\mathrm{PO}_{4}\right)_{3} \mathrm{~F}$ & $26,08 \%$ \\
Carbonato de Cálcio & $\mathrm{CaCO}_{3}$ & $13,04 \%$ \\
Óxido de Urânio & $\mathrm{UO}_{2}$ & $6,52 \%$ \\
\hline
\end{tabular}

Além da presença desses minerais, tem-se os argiolominerais, minerais característicos das argilas, onde quimicamente são silicatos de alumínio ou magnésio hidratados, contendo outros tipos de elementos como ferro, potássio, lítio e outros. Os principais grupos de argilominerais são: caulinita, ilita e esmectitas ou montmorilonita. Foram registrados nessa área com base nos difratogramas de raios- $X$, apenas a caulinita (Figura 1), vermiculita (Figura 2) e montmorilonita (Figura 3), onde o que diferencia estes argilominerais é basicamente o tipo de estrutura e as substituições que podem ocorrer dentro da estrutura, do alumínio por magnésio ou ferro, e do silício por alumínio ou ferro, principalmente, e consequente neutralização das cargas residuais geradas pelas diferenças de cargas elétricas dos íons por alguns cátions.

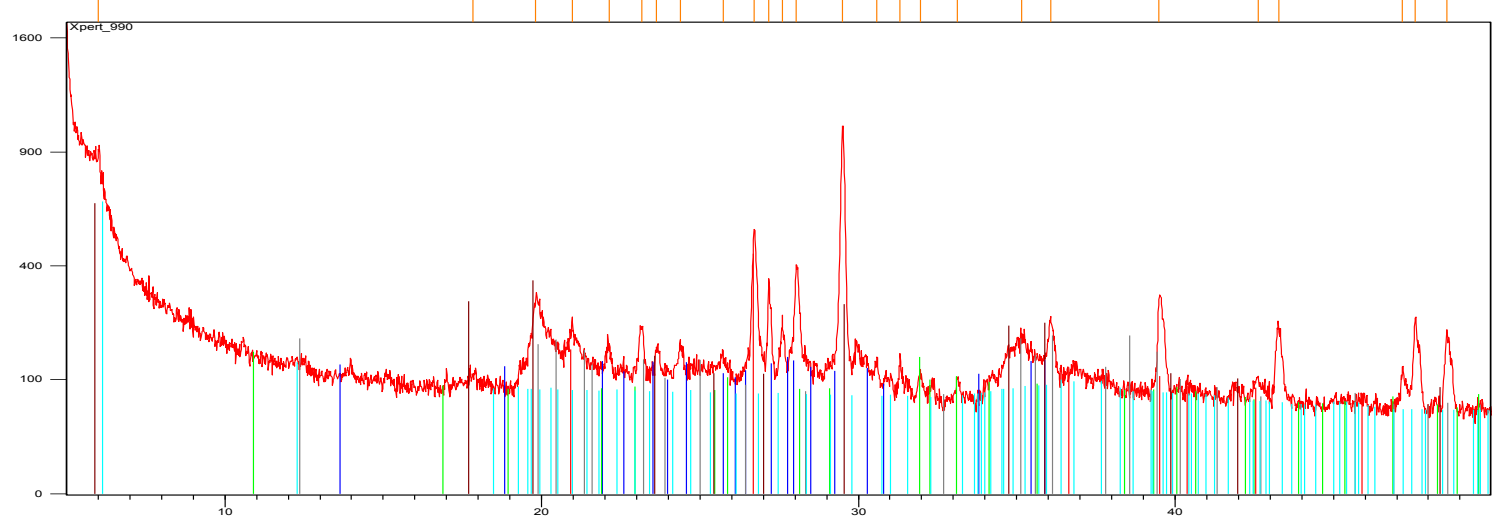

Figura 1: Difratograma de raio-X de amostra D12 contendo caulinita que apresenta uma distância basal de primeira ordem de 7,1Ă que em termos de identificação por $2 \theta$ é de 12,45.

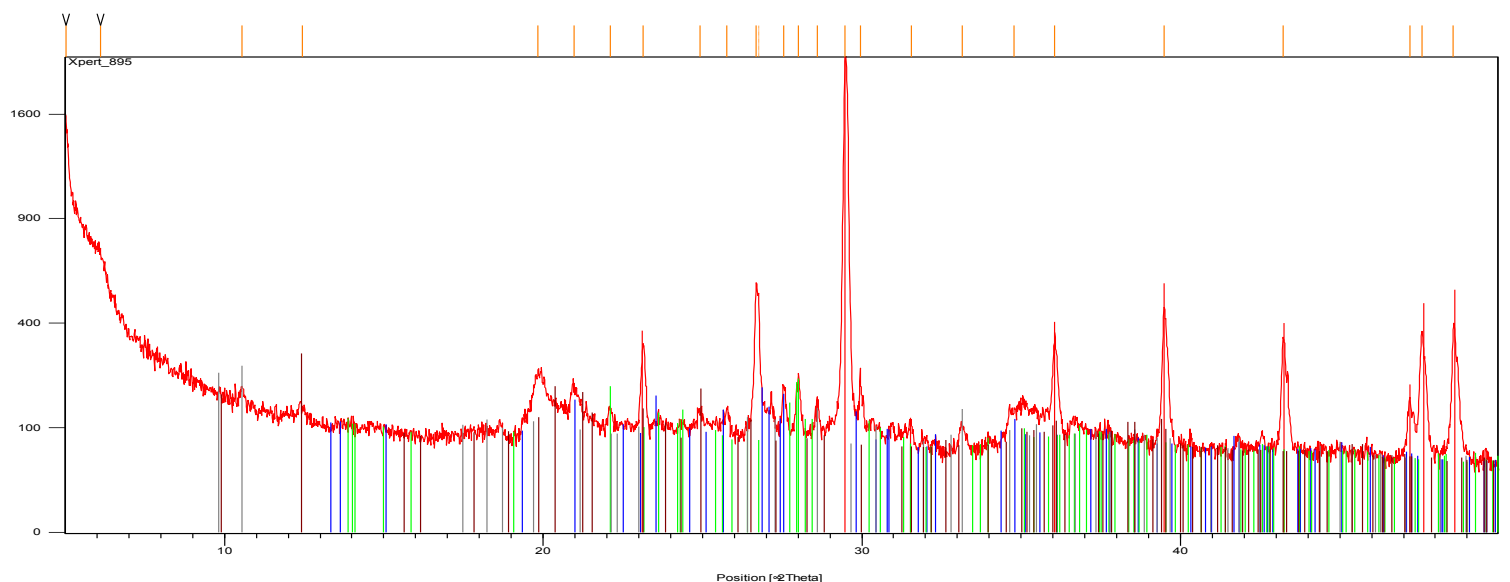

Figura 2: Difratograma de raio-X de amostra D8 contendo montmorilonita que apresenta uma distância basal de primeira ordem de 14,7Ă que em termos de identificação por $2 \theta$ é de 6,1. 


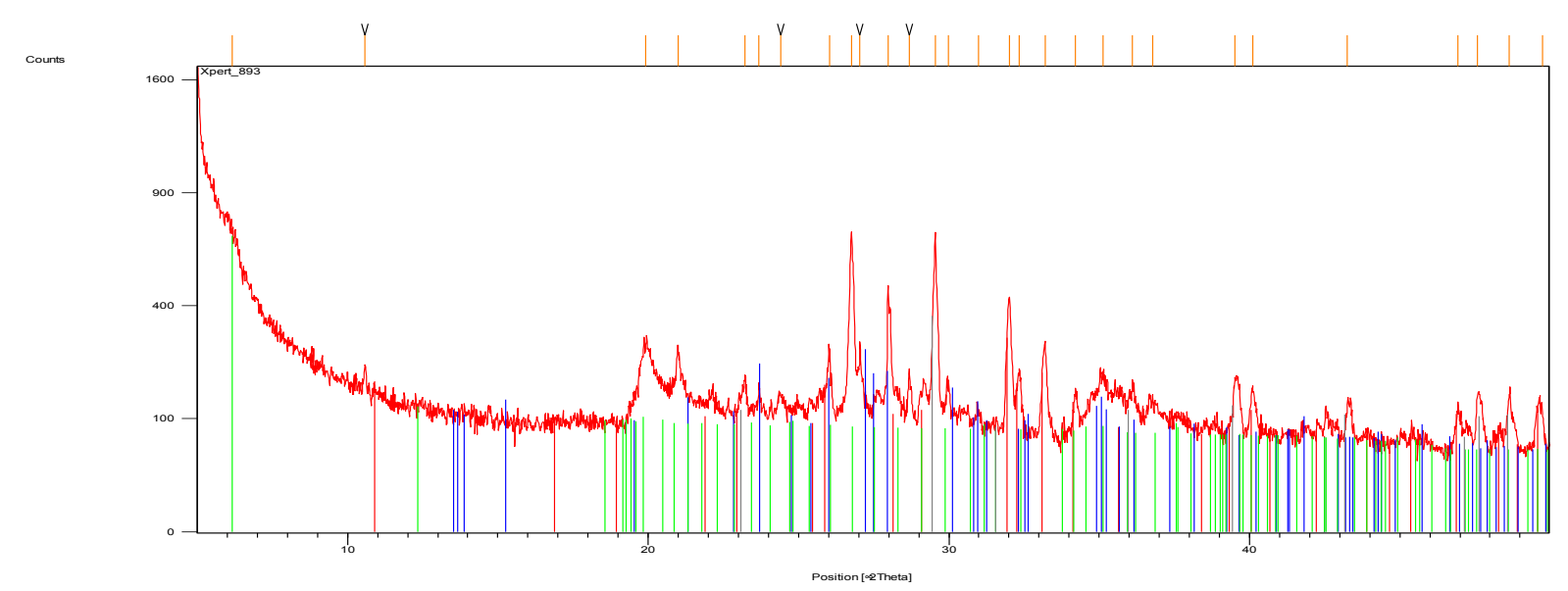

Figura 3: Difratograma de raio-X de amostra D30 contendo vermiculita que apresenta uma distância basal de primeira ordem de 14,3Ă que em termos de identificação por $2 \theta$ é de 6,2.

\section{CONSIDERAÇÕES FINAIS}

Nos resultados obtidos na Difração de Raios-X juntamente com os dados do mapa dos solos do Ceará da EMBRAPA. Tem-se que nessa região encontram-se os solos argissolo vermelhoamarelo eutróficos, luvissolos e neossolos litólicos eutróficos.

Os argissolos vermelho-amarelo eutróficos, concentram-se na porção Sudoeste da região de Itataia e espaçadamente em vários outros pontos, compreendendo solos com horizonte $\mathrm{B}$ textural, não hidromórficos e com argila de atividade baixa.

Os solos luvissolos são encontrados com frequência nos sertões cearense, sendo caracterizado nessa região como solos minerais pouco profundos, não hidromórficos, com argila de atividade alta, eutróficos, horizonte $A$ fraco ou moderado, consistência dura ou muito dura, quando secos, estrutura maciça ou em blocos fracamente desenvolvidos.

Os solos neossolos litólicos eutróficos são muito pouco desenvolvidos, rasos, não hidromórficos apresentando horizonte $A$ diretamente sobre a rocha ou horizonte $C$ de pequena espessura. São normalmente pedregosos e/ou rochosos, moderadamente a excessivamente drenados com horizonte $A$ pouco espesso, cascalhento, de textura predominantemente média.

Portando, os resultados da análise de Difração de Raios $-X$ com base na fração mineral para as amostras analisadas, verificou-se que as amostras de solo possuem uma maior quantidade de quartzo $\left(\mathrm{SiO}_{2}\right)$, fluorapatita $\left(\mathrm{Ca}_{5}\left(\mathrm{PO}_{4}\right)_{3} \mathrm{~F}\right)$, carbonato de cálcio $\left(\mathrm{CaCO}_{3}\right)$ e a presença de óxido de urânio, referindo-se assim a uma anomalia. Além disso detectou-se a presença de argilominerais, como, a caulinita, vermiculita e montmorilonita.

\section{REFERÊNCIAS}

Allen, B. L.; Hajek, B. F. (1989) Mineral occurrence in soil environments. In: Dinauer, R.C.; Kissel, D. E. (Eds.) Minerals in soil environments. n. 1. Madison: Soil Science Society of America Book Series. Cap. 5. P. 200-264. 
Almeida F.F.M. de, Hasui Y., Brito-Neves B.B de, Fuck R. A. (1981). Brazilian Structural Provinces: an introduction. Earth-Sci. Rev., 17: 1-29

Almeida F.F.M. de, Hasui Y., Brito-Neves B.B de, Fuck R. A. (1977). As províncias estruturais do Brasil. In: SBG, Simp Geol. Nordeste, 8, Bol. Esp., 12p.

Brindley, G. W.; Brown, G. (1980) Crystal structures of clay minerals and their X- Ray identification. London: Mineralogical Society. P. 495.

Brito Neves, B. B. de. (1975). Regionalização geotectônica do Pré-cambriano nordestino. São Paulo. Tese de Doutorado. Instituto de Geociências, Universidade de São Paulo, Tese de Livre Docência 198p.

Brito Neves, B.B.; Santos, E.J. DOS; Van Schmus, W.R. (2000) Tectonic history of the Borborema Province, Northeastern Brazil - In Cordanl, V.G. et al., Editors - Tectonic Evolution of South America. Rio de Janeiro. P. 151-182.

Buckman, H. O. (1976) Natureza e propriedades do solo, 4a Ed, Rio de Janeiro: Livraria Freitas Bastos S.A. P 647.

Caby R., Arthaud M. (1986) Major Precambrian nappes of the Brazilian belt, Ceará, northeast Brazil. Geology 14. P. 571-874.

Caby, R.; Sial, A.N.; Arthaud, M.H.; Vauchez, A., (1991) Crustal evolution and the Brasiliano Orogeny in Northeast Brazil. In: Dallmeyer, R.D. \& Lecorche, J.P. eds. The West African orogens and circum-Atlantic correlatives. Berlin, Springer-Verlag. P. 373-397.

Caby, R.; Arthaud, M.; Archanjo, C.J. (1995). Lithostratigraphy and petrostructural characterization of supracrustal units in the Brasiliano Belt of Northeast Brazil: geodynamic implications. Jour. South Am. Earth Sci., 8, P. 235-246.

Castro, G. L.; Parente, C. V.; Verissimo, C. U. V.; Sial, A. N.; Garcia, M. G. M.; Melo, R. C.; Santos, A. A.; Santos, R. V. (2005) Isótopos de Carbono e Oxigênio dos Mármores associados com os Depósitos Uraníferos de Itataia - CE. Revista Brasileira de Geociências, v. 35. P. 199-208.

Cullity, B. D. Elements of X-Ray Diffraction. Ed. 2. Massachusetts: Addison-Wesley Publishing Company, Inc., 1978. P. 555.

Companhia De Pesquisa De Recursos Minerais (CPRM). (2000) Mapa Geológico do Estado do Rio de Janeiro. Disponível em <http://geobank.sa.cprm.gov.br >. Acesso 14 jun. 2014.

Fetter, A.H. (1999) U/Pb and Sm/Nd geocronological constraints on the crustal framework and geologic history of Ceará State, NW Borborema Province, NE Brazil: implications for the assembly of Gondwana. PhD Thesis, Dep. Geology, Kansas University, Lawrence, 164p.

Fetter, A. H, Dos Santos, T. J. S., Van Schmus, W. R., Hackspacher, P. C., Brito Neves, B. B., Arthaud, M. H., Nogueira Neto, J. A. \& Wernick, E. (2003). Evidence for Neoproterozoic continental arc magmatism in the Santa Quitéria batholith of Ceará State, NW Borborema Province, NE Brazil: implications for assembly of west Gondwana. Gondwana Research, 6. P. 265-273.

Fontes, M.P.F. (2002) Mineralogia do solo (Versão Resumida). Viçosa, MG, Universidade Federal de Viçosa.

Hill, R. J.; Howard, C. J. (1987) Quantitative phase analysis from neutron powder diffraction data 
using the Rietveld Method. Journal os Appplied Crytallography, v.20, P. 467-474.

Hill, R. J.; Madsen, I.C. (2006) Sample preparation, instrument selection and data collection. In: DAVID, W. I. F.; SHANKLAND, K.; MCCUSKER, L. B.; BAERLOCHER, Ch (Eds.) Structure determination from powder diffraction data. Oxford, UK: Oxford University Press. Cap. 6. P. 98-117.

INB, Indústrias Nucleares Brasileiras. Projeto Santa Quitéria. Disponível em: <https:www.inb.gov.br>. Acesso em: 05 junho 2014.

IPECE. Instituto de Pesquisas e Estudos Econômicos do Ceará. (2012) Anuário estatístico do Ceará. Fortaleza. P. 245.

Jardim de Sá, E.F. (1994) A Faixa Seridó (Província Borborema, NE do Brasil) e o seu significado geodinâmico na Cadeia Brasiliana/Pan-Africana. Brasilia. 804 p. (Tese de Doutorado, Instituto de Geociências da Universidade de Brasilia).

Mendonça, J. G S.; Braga, A. P. G.; Campos, M. DE. (1980) Considerações sobre a mineralização fósforo-uranífera da Jazida de Itataia. Anais do XXXI Congr. Bras. De Geologia. V. 4, p. 24722486.

Mendonça J.C.G.S., Campos M., Braga A.P.G., Souza E.M. 1982. Caracterização estratigráfica dos metassedimentos da região de Itataia - Ceará (Grupo Itataia). In: SBG, Cong. Bras. Geol., 32, 1:325-338.

Mendonça J.C.G.S.; Campos M.; Braga A.P.G.; Souza E.M.; Favali J.C.; Leal J.R.L.V. (1985) Jazida de Urânio de Itataia-CE. In: Principais Depósitos Minerais do Brasil, DNPM, v.1, P. 121-131.

NUCLEBRÁS. (1984) Relatório de Geotecnia Semi-Detalhe. Circulação interna da Indústria de Nucleares do Brasil S/A, Fortaleza-CE, P. 52

Pessoa R. R., Archanjo C. J. (1984) Tectônica de empurrões na região de Troia-Ce. 33rd Congress of Brazilian Geology, Rio de Janeiro, Sociedade Brasileira de Geologia. P. 1721-1728,.

Pessoa D. E., Brito Neves B. B., Kawashita K., Pessau D. R., Fack A. R. (1986) Contribuição aos estudos da evolução geocronológica do maciço de Troia-Ce. 12 Simpósio de Geologia do Nordeste, Joao Pessoa, Brazil. P. 75-93.

Schulze, D. G. (1989) Introdution to soil mineralogy. In: DINAUER, R. C.; KISSEL, D. E. (Eds.) Minerals in soil environments. n. 1. Madison: Soil Science Socity of America Book Series, . Cap. 1. P. 1-34.

Van Schmus, W.R.; Brito Neves, B.B.; Hackspacher P.; Fetter A.H.; Kozuch M.; Dantas E.L. \& Babinski, M. (1998) The Borborema Province: a collage of polycyclic crustal domains in NE Brazil. In: International Conf. Basement Tectonic, 14, Ouro Preto, Extended Abstracts. P. 8083.

Whitting, L.D. (1965) X-ray techniques for mineral identification and mineralogical composition. In: Black, C. A (Ed). Methods of Soil Analysis, part 1, Physical and Mineralogical Properties. Madison: American Society of Agronomy. Cap. 49. P. 671-698. 